\title{
Target Coordinates Estimation by Passive Radar with a Single non-Cooperative Transmitter and a Single Receiver
}

\author{
Ali Kazem, Adnan Malki, and Anas Mahmoud Almanofi
}

\begin{abstract}
Passive radar is a bistatic radar that detects and tracks targets by processing reflections from non-cooperative transmitters. Due to the bistatic geometry for this radar, a target can be localized in Cartesian coordinates by using one of the following bistatic geometries: multiple non-cooperative transmitters and a single receiver, or a single non-cooperative transmitter and multiple receivers, whereas the diversity of receivers or non-cooperative transmitters leads to extra signal processing and a ghost target phenomenon. To mitigate these two disadvantages, we present a new method to estimate Cartesian coordinates of a target by a passive radar system with a single non-cooperative transmitter and a single receiver. This method depends on the ability of the radar receiver to analyze a signal-tonoise ratio (SNR) and estimate two arrival angles for the target's echo signal. The proposed passive radar system is simulated with a Digital Video Broadcasting-Terrestrial (DVB-T) transmitter, and the simulation results show the efficiency of this system compared with results of other researches.
\end{abstract}

Index terms - passive radar, target coordinates, single noncooperative transmitter, single receiver, signal-to-noise ratio, two arrival angles.

\section{INTRODUCTION}

$\mathrm{P}$ ASSIVE radar is a system that does not transmit any signal compared with an active radar system. It detects and tracks targets by applying radar measurements to emissions of non-cooperative transmitters. Therefore, the passive radar has the advantage that it is resistant to jammers [1], [2]. This radar is equipped with two antennas: The first antenna is a surveillance antenna, which receives targets' echoes and multipath signals, whereas the second antenna is a reference antenna, which receives a reference signal [3]. The reference signal is reconstructed to detect targets [4].

Passive radar has been studied in many researches, such as studying of targets detection [5]-[7], studying of signals of

Manuscript received December 26, 2019; revised April 2, 2020. Date of publication May 4, 2020. Date of current version May 4, 2020. The associate editor prof. Zoran Blažević has been coordinating the review of this manuscript and approved it for publication.

Authors are with the Higher Institute for Applied Sciences and Technology, Damascus, Syria (e-mails: ali.kazem@hiast.edu.sy, adnan.malki@hiast.edu.sy, anas.almanofi@hiast.edu.sy).

Digital Object Identifier (DOI): 10.24138/jcomss.v16i2.984 non-cooperative transmitters and determining of the best signal for this radar [8]-[10], [1], [6], studying of an effect of a reference signal on a surveillance channel [11], [12], [2], and localizing of targets in Cartesian coordinates [13]-[20].

Passive radar localizes a target in Cartesian coordinates by using one of the following bistatic geometries: multiple noncooperative transmitters and a single receiver [13]-[16], a single non-cooperative transmitter and multiple receivers [17], [18], or multiple non-cooperative transmitters and multiple receivers [19], [20], then the target is localized by determining ellipsoid intersections corresponding to the transmitterreceiver pairs [1], [13]. This process leads to a ghost target phenomenon that generates false targets [1], and the diversity of receivers or non-cooperative transmitters leads to extra signal processing [21]. Therefore, we want to mitigate the two mentioned disadvantages and estimate Cartesian coordinates of a target by proposing a new method with a passive radar system that has the bistatic geometry: a single non-cooperative transmitter and a single receiver.

In the same context, a passive radar system with a noncooperative transmitter and a receiver was studied in many researches [22]-[24]. They presented this system with a single receiver channel to receive two signals: a reference signal and a surveillance signal, but they cleared up the detection of a target by processing a (range-Doppler) diagram at the output of a matched filter. Authors of these researches were not able to estimate Cartesian coordinates of the target because the parameter (range) is a bistatic range, which does not refer to the range between the target and the receiver. Therefore, the diversity of receivers or non-cooperative transmitters should be used for localizing a target in Cartesian coordinates.

This paper is organized as follows. Section II introduces the proposed solution for estimating Cartesian coordinates of a target by the passive radar system with one non-cooperative transmitter and one receiver. Section III presents the initial conditions for simulating the proposed passive radar system. Section IV shows the simulation results and concentrates on the discussion of these results. Section V concludes the paper. For simplicity, we consider that a transmitter is a noncooperative transmitter and target's coordinates are Cartesian coordinates. 


\section{PROPOSED SOLUTION}

\section{A. Proposed Bistatic Geometry}

It consists of one transmitter and one receiver, in taking into consideration that there is only one target, as shown in Fig. 1.

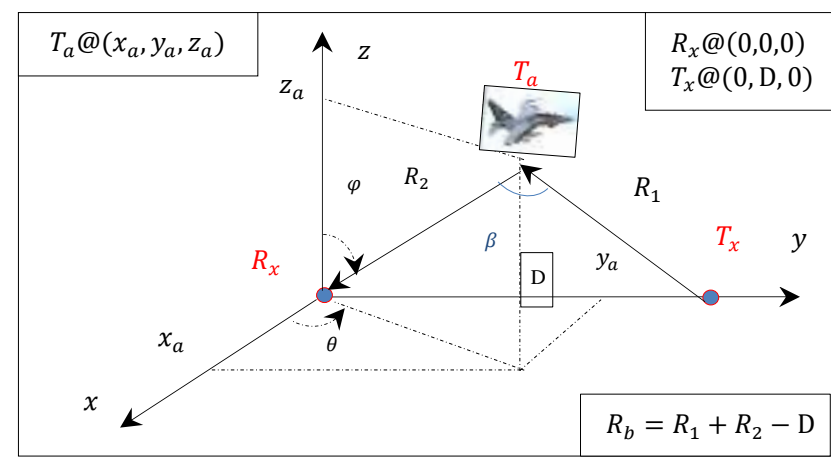

Fig. 1. Proposed passive radar geometry

where $T_{x}$ is the transmitter, $R_{x}$ is the receiver with two antennas, $T_{a}$ is the target, $R_{1}$ is the range between the transmitter and the target, $R_{2}$ is the effective range, $R_{b}$ is the bistatic range, $\mathrm{D}$ is the distance between the transmitter and the receiver, $\left(x_{a}, y_{a}, z_{a}\right)$ are the target coordinates, $\beta$ is the bistatic angle, $\varphi$ is the arrival angle of the target's echo signal in the elevation direction, and $\theta$ is the arrival angle of the same signal in the azimuth direction.

\section{B. Proposed Method}

It depends on processing a mathematical approach for the proposed passive radar geometry, whereas this approach links between estimated parameters for the target's echo signal and the distance between the transmitter and the receiver. After processing the mentioned approach, we can estimate the effective range and the target coordinates.

The mathematical approach depends on Cassini ovals, which explain a status of a presence of the following three points in a Cartesian coordinate system: a fixed transmitter, a fixed receiver and a target, thus multiplying distances to two fixed points is related to SNR variations of the target's echo signal [25], [3]. The mathematical expression for that approach is given in (1) and (2).

$$
\begin{gathered}
\left\|\overrightarrow{T_{x} T_{a}}\right\|^{2} *\left\|\overrightarrow{T_{a} R_{x}}\right\|^{2}=R_{1}^{2} * R_{2}^{2}=R_{M}^{4} \\
\left\{x_{a}^{2}+\left(\mathrm{D}-y_{a}\right)^{2}+z_{a}^{2}\right\} *\left\{x_{a}^{2}+y_{a}^{2}+z_{a}^{2}\right\}=R_{M}^{4}
\end{gathered}
$$

where $R_{M}$ is the equivalent range; $R_{M}=\sqrt{R_{1} R_{2}}$.

We convert (2) from the Cartesian coordinate system $\left(x_{a}, y_{a}, z_{a}\right)$ to the spherical coordinate system $\left(R_{2}, \varphi, \theta\right)$ by substituting (3) in (2), whereas (3) is the equation of the target coordinates, which are results from Fig. 1.

$$
\left[\begin{array}{l}
x_{a} \\
y_{a} \\
z_{a}
\end{array}\right]=R_{2} *\left[\begin{array}{c}
\sin (\varphi) \cos (\theta) \\
\sin (\varphi) \sin (\theta) \\
\cos (\varphi)
\end{array}\right]
$$

After substituting (3) in (2), we obtain (7), which represents the mathematical description for a passive radar system with a single transmitter, a single receiver and a target.

$$
\begin{aligned}
\left\{R_{2}^{2} \sin ^{2}(\varphi) \cos ^{2}(\theta)+\mathrm{D}^{2}+R_{2}^{2} \sin ^{2}(\varphi) \sin ^{2}(\theta)\right. & \\
& \left.-2 \mathrm{D} R_{2} \sin (\varphi) \sin (\theta)+R_{2}^{2} \cos ^{2}(\varphi)\right\} * R_{2}^{2} \\
& =R_{M}^{4}
\end{aligned}
$$

$$
\begin{gathered}
\left\{R_{2}^{2} \sin ^{2}(\varphi) *\left(\cos ^{2}(\theta)+\sin ^{2}(\theta)\right)+\mathrm{D}^{2}-2 \mathrm{D} R_{2} \sin (\varphi) \sin (\theta)\right. \\
\left.+R_{2}^{2} \cos ^{2}(\varphi)\right\} * R_{2}^{2}=R_{M}^{4}
\end{gathered}
$$$$
\left\{R_{2}^{2}\left(\sin ^{2}(\varphi)+\cos ^{2}(\varphi)\right)+\mathrm{D}^{2}-2 \mathrm{D} R_{2} \sin (\varphi) \sin (\theta)\right\} * R_{2}^{2}=
$$$$
R_{M}^{4}
$$

$$
R_{2}^{4}-2 \mathrm{D} \sin (\varphi) \sin (\theta) R_{2}^{3}+\mathrm{D}^{2} R_{2}^{2}-R_{M}^{4}=0
$$

Notice that (7) is a fourth-order equation that has four solutions: two imaginary solutions, a negative solution and a positive solution, whereas the positive solution is the correct variable $\left(R_{2}\right)$. The parameters of this equation are: (D, $\varphi$, $\theta$ and $R_{M}$ ), which should be estimated to complete the estimation of the target coordinates. These parameters are estimated as follows:

a) The parameter (D) is identified.

b) The two angles $(\varphi$ and $\theta)$ are estimated by many algorithms, such as MUSIC (Multiple Signal Classification) and ESPRIT (Estimation of Signal Parameters via Rotational Invariance Technique). Many researches have indicated that the MUSIC algorithm has high performance for estimating the two arrival angles [26], [27], so we will use the 2-dimensional MUSIC algorithm in this paper. The 2D-MUSIC algorithm is an algorithm that uses a 2D-array antenna and depends on processing and analyzing the output of the array antenna for forming the shape of a spatial spectrum function. Then the two arrival angles of the observed signal are estimated by applying the Maximum Likelihood method to the shaped function [28]-[31]. The estimation accuracy of this algorithm is related to the following parameters: SNR, the number of elements of the array antenna, duration of the processed signal in Baseband, and a search resolution in the azimuth and elevation directions [29].

c) The parameter $\left(R_{M}\right)$ is estimated by measuring and analyzing SNR of the target's echo signal. It is given in (9) and (10), and the parameter (SNR) is given in (8), [3], [10].

$$
\begin{gathered}
S N R=\frac{P_{t} G_{t} G_{r_{S A}} \lambda^{2} \sigma_{R C S}}{(4 \pi)^{3} K T_{0} B F L_{t} L_{r} R_{M}^{4}} \\
R_{M}^{4}=R_{1}^{2} R_{2}^{2}=\frac{P_{t} G_{t} G_{r_{S A}} \lambda^{2} \sigma_{R C S}}{(4 \pi)^{3} K T_{0} B F L_{t} L_{r} S N R}
\end{gathered}
$$




$$
R_{M}^{4}=\rho \frac{\sigma_{R C S}}{S N R}
$$

where $P_{t}$ is the transmitted power (watt), $G_{t}$ is the transmitter antenna gain, $G_{r_{S A}}$ is the surveillance antenna gain, $\lambda$ is the transmitter wavelength $(\mathrm{m}), \sigma_{R C S}$ is the bistatic radar cross section $\left(\mathrm{m}^{2}\right), K$ is Boltzmann's constant, $T_{0}$ is the effective noise temperature, $B$ is the receiver bandwidth $(\mathrm{Hz}), F$ is the receiver noise figure, $L_{t}$ is the transmitter system losses, $L_{r}$ is the receiver system losses, and $\rho$ is the studied system constants.

Whenever the receiver of the proposed passive radar system is able to estimate the two angles $(\theta$ and $\varphi)$ and analyze the parameter (SNR) for the target's echo signal optimally, then the effective range and the target coordinates are estimated with higher estimation accuracy. In the same context, if the mentioned receiver estimates the parameters $\left(\theta, \varphi\right.$ and $\left.R_{b}\right)$, then the estimated coordinates are wrong, because the bistatic range $\left(R_{b}\right)$ refers to the summation of the two ranges $\left(R_{1}, R_{2}\right)$, see Fig. 1 .

Note: At measuring the parameter (SNR), we should pay attention to the parameter (RCS), which must be determined or estimated for the proposed method. Many researches have indicated that it can be estimated by one of the following two options:

a) Using statistical methods, such as a Hidden Markov chain (Bayesian filtering). In this option, the parameter (RCS) is estimated by estimating and analyzing parameters of a target's echo signal [32]-[39].

b) Using a database that contains values of RCS for various target classes. This option depends on radar measurements [40]-[42].

\section{Simulating Proposed Passive RadAR System}

MATLAB software is used for simulating the proposed passive radar system that consists of the following parts: The DVB-T transmitter, Additive White Gaussian Noise channel with one observed target, and the receiver that has two antennas, as shown in Fig. 2.

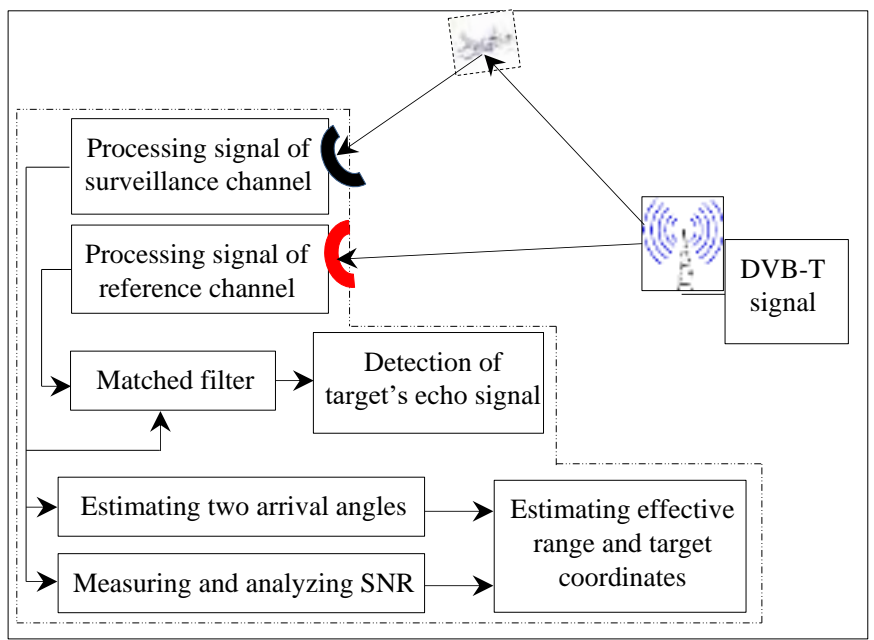

Fig. 2. Block diagram for simulation and processing
We consider that the observed target moves according to the path shown in Fig. 3, whereas its instantaneous position is given in (11).

$$
\left[\begin{array}{l}
x_{a}(t+1) \\
y_{a}(t+1) \\
z_{a}(t+1)
\end{array}\right]=\left[\begin{array}{l}
x_{a}(t) \\
y_{a}(t) \\
z_{a}(t)
\end{array}\right]+\left[\begin{array}{l}
v_{x}(t) \\
v_{y}(t) \\
v_{z}(t)
\end{array}\right] \Delta t
$$

where $(t+1)$ is the current time step, $t$ is the previous time step, $\left(v_{x}, v_{y}, v_{z}\right)_{(t)}$ are the Cartesian components for the target speed at the previous time step $(t)$, and $\Delta t$ is the time difference between two consecutive measurements.

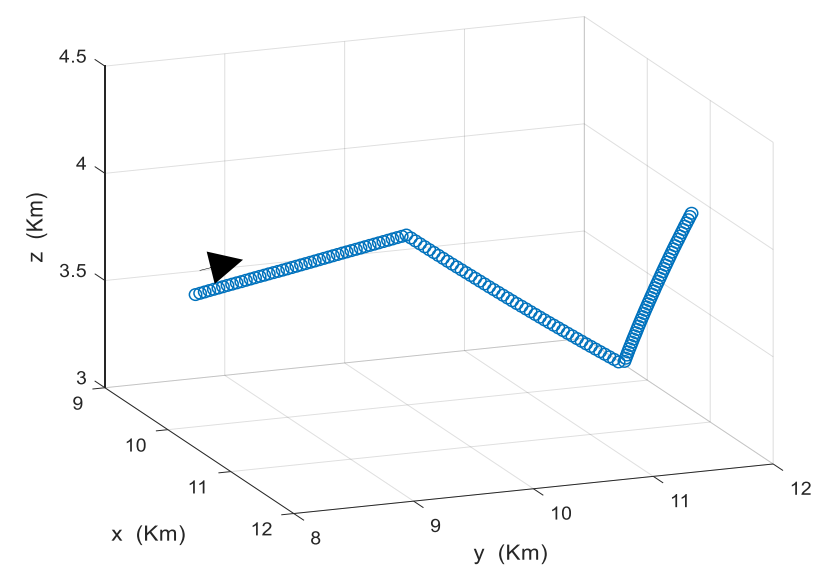

Fig. 3. Path of observed target

To complete the description of this simulation, we add the technical characteristics for the transmitter, the receiver and the observed target, as listed in Table I.

TABLE I

\begin{tabular}{|c|c|c|c|c|}
\hline \multirow{5}{*}{ 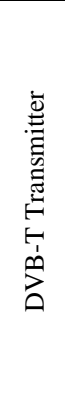 } & ERP & $50(\mathrm{KW})$ & $\begin{array}{l}\text { Guard } \\
\text { interval }\end{array}$ & $1 / 32$ \\
\hline & $\begin{array}{l}\text { Carrier } \\
\text { frequency }\end{array}$ & $474(\mathrm{MHz})$ & $\begin{array}{l}\text { Duration of } \\
\text { OFDM } \\
\text { symbol }\end{array}$ & $0.924(\mathrm{~ms})$ \\
\hline & Bandwidth & $8(\mathrm{MHz})$ & $\begin{array}{l}\text { Cartesian } \\
\text { coordinates }\end{array}$ & {$[0, \mathrm{D}, 0]^{T}$} \\
\hline & $\begin{array}{l}\text { Transmission } \\
\text { mode/ } \\
\text { modulation }\end{array}$ & $\begin{array}{l}8 \mathrm{~K} \text { mode } / \\
64 \mathrm{QAM}\end{array}$ & $\mathrm{D}$ & $5(\mathrm{Km})$ \\
\hline & Code Rate & $7 / 8$ & $L_{t}$ & $1(\mathrm{~dB})$ \\
\hline \multirow{5}{*}{ 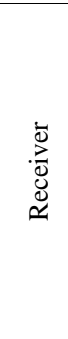 } & $\begin{array}{l}\text { surveillance } \\
\text { antenna gain }\end{array}$ & $22(\mathrm{~dB})$ & $\Delta t$ & $0.1499(\mathrm{~s})$ \\
\hline & $\begin{array}{l}\text { reference } \\
\text { antenna gain }\end{array}$ & $2.5(\mathrm{~dB})$ & $\mathrm{T}_{\mathrm{P}}$ & $0.924(\mathrm{~ms})$ \\
\hline & $\begin{array}{l}\text { Cartesian } \\
\text { coordinates }\end{array}$ & {$[0,0,0]^{T}$} & $L_{r}$ & $1(\mathrm{~dB})$ \\
\hline & $\left(N_{x}, N_{y}\right)$ & $(3,3)$ & $F$ & $2(\mathrm{~dB})$ \\
\hline & \multicolumn{4}{|c|}{$\begin{array}{c}\text { Search resolution of 2D-MUSIC algorithm is } 0.1^{\circ} \text { in azimuth and } \\
\text { elevation directions }\end{array}$} \\
\hline \multirow{2}{*}{$\begin{array}{l}\vec{D} \\
\overbrace{0}^{0} \\
0 \\
0 \\
0 \\
0\end{array}$} & $\begin{array}{l}\text { Monostatic } \\
\text { RCS }\end{array}$ & $6\left(m^{2}\right)$ & $\begin{array}{l}\text { Initial } \\
\text { coordinates }\end{array}$ & $\begin{array}{l}{[9.5,8.5,3.5]^{T}} \\
(K m)\end{array}$ \\
\hline & speed & $\begin{array}{c}250 \\
(\mathrm{~m} / \mathrm{sec})\end{array}$ & $\begin{array}{l}\text { Bistatic } \\
\text { Doppler } \\
\text { Frequency }\end{array}$ & $\begin{array}{l}{[-771-758]} \\
\quad(H z)\end{array}$ \\
\hline
\end{tabular}

TeChNiCAl CHARACTERISTICS FOR TRANSMitTER, RECEIVER AND TARgET 
where ERP refers to (Effective Radiated Power), OFDM refers to (Orthogonal Frequency Division Multiplexing), $T$ is the transpose of a matrix, $\left(N_{x}, N_{y}\right)$ are the numbers of elements of the $2 \mathrm{D}$ array antenna in $x$-direction and $y$-direction, and $\mathrm{T}_{\mathrm{P}}$ is the processing duration per each measurement.

This simulation has been achieved with the following considerations:

a) The transmitted signal is a DVB-T signal because many researches have indicated that it is the best signal for passive radar. This is because of the following reasons: First, it is a digital signal, so a reference signal can be recreated perfectly. Second, it has a small Monostatic range resolution (approximately $20(\mathrm{~m})$ ), and finally, it is robust to multipath fading because it depends on the OFDM modulation technique [1], [8]-[10].

b) The parameter (RCS) is estimated by the method of [32], and the maximum estimation error is $(0.1 * \mathrm{RCS})$ [36], [37]. For simplicity, we consider that the parameter (RCS) is constant during the simulation.

c) Bistatic RCS is enhanced in a compare with Monostatic RCS at the frequency bands (UHF \& VHF), whereas the enhancement is typically $7(\mathrm{~dB})[43]$.

d) We do not use interference suppression techniques between the reference signal and the surveillance channel because the range of the parameter $(\mathrm{SIR})$ is $\left[\begin{array}{ll}-69.8 & -65.7\end{array}\right](\mathrm{dB})$, which is between $-70(\mathrm{~dB})$ and $-60(\mathrm{~dB})$ [11], where SIR is the signal-to-interference ratio.

e) The observed target is detected with a false alarm probability $\left(10^{-5}\right)$, whereas the SNR of the target's echo signal changes according to Fig. 4.

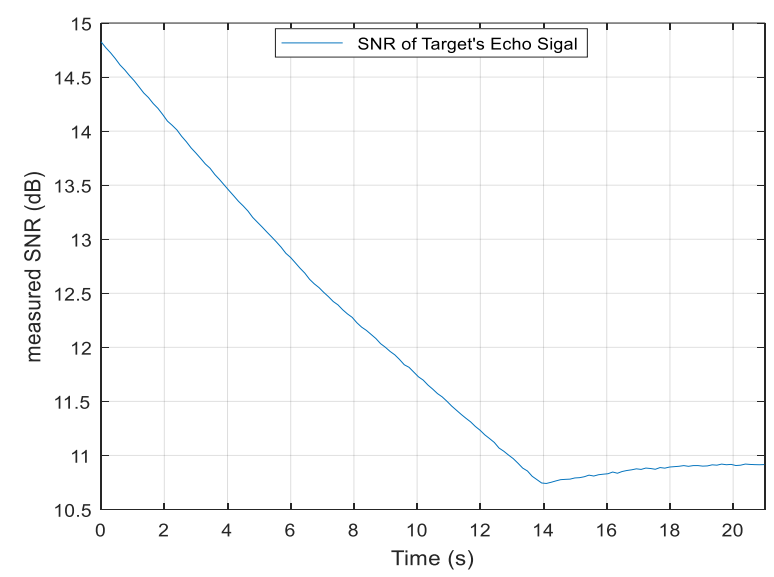

Fig. 4. Measured SNR as a function to time

\section{RESULTS AND DISCUSSION}

After executing the simulation of the proposed passive radar system, we will find the following results, with taking into consideration these points: 1) An estimation error is calculated as the difference between a real value and an estimated value. 2) A trusted estimation domain and estimation accuracy are related to a standard deviation of estimation errors.

The two arrival angles of the target's echo signal have been estimated by the 2D-MUSIC algorithm, and the maximum estimation errors are as follows: $\left(0.055^{\circ}\right)$ for the elevation angle and $\left(0.24^{\circ}\right)$ for the azimuth angle. Figures (5 and 6) show the real values, the estimated values and the trusted estimation domain for each angle.

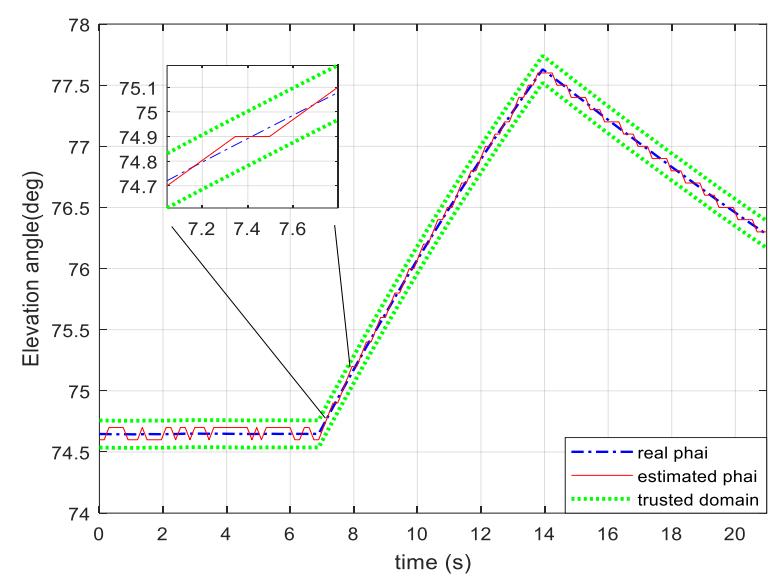

Fig. 5. Real and estimated elevation angle

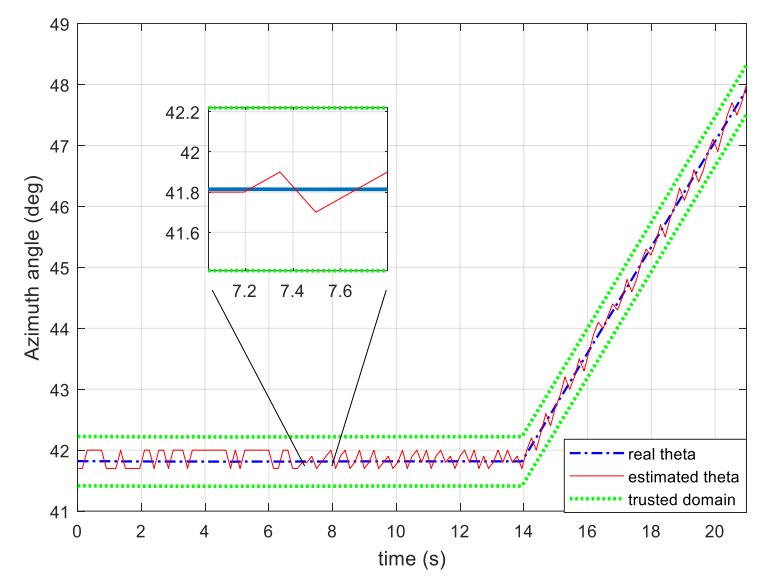

Fig. 6. Real and estimated azimuth angle

The effective range has been estimated by solving (7), and the maximum estimation error is $(384(\mathrm{~m}))$. Figure 7 shows the real values, the estimated values and the trusted estimation domain for this range.

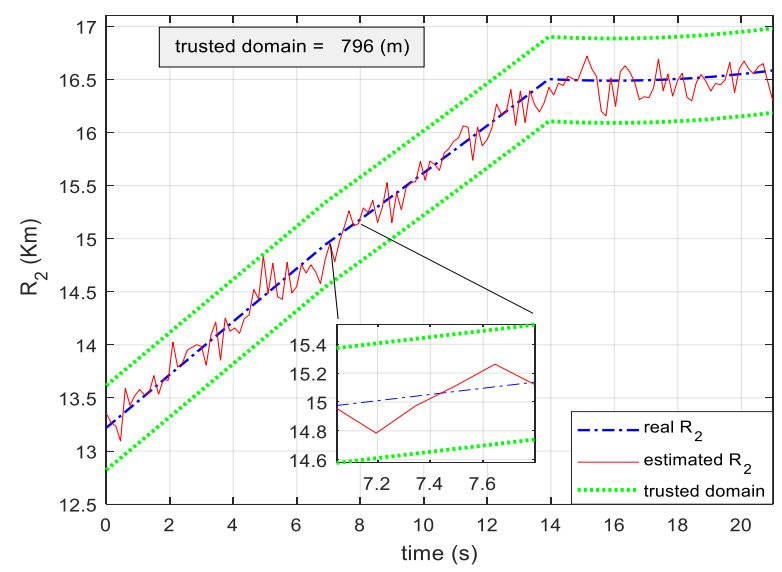

Fig. 7. Real and estimated effective range 
The target coordinates have been estimated by estimating the two arrival angles of the target's echo signal and the effective range, and the maximum estimation errors of these coordinates are as follows: $258(\mathrm{~m})$ for the $\left(x_{a}\right)$ coordinate, $284(\mathrm{~m})$ for the $\left(y_{a}\right)$ coordinate and $89(\mathrm{~m})$ for the $\left(z_{a}\right)$ coordinate. Figures $(8,9$ and 10) show the real values, the estimated values and the trusted estimation domain for each coordinate.

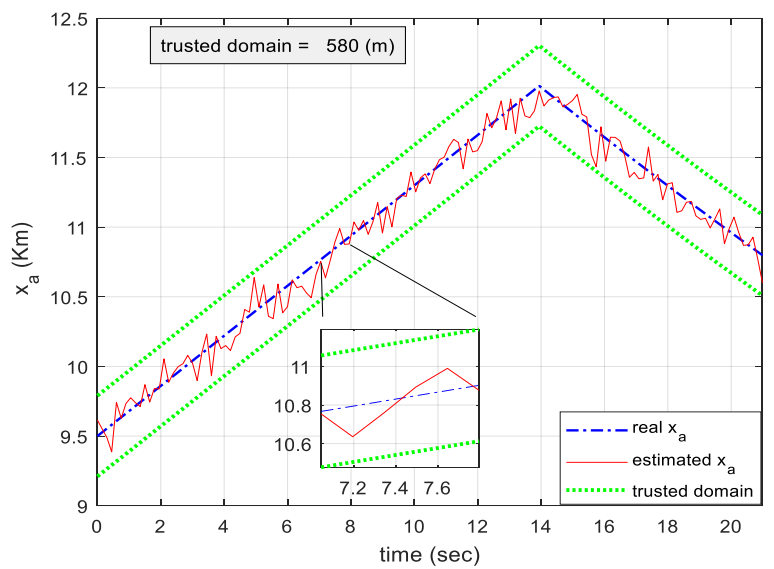

Fig. 8. Real and estimated $\left(x_{a}\right)$ coordinate

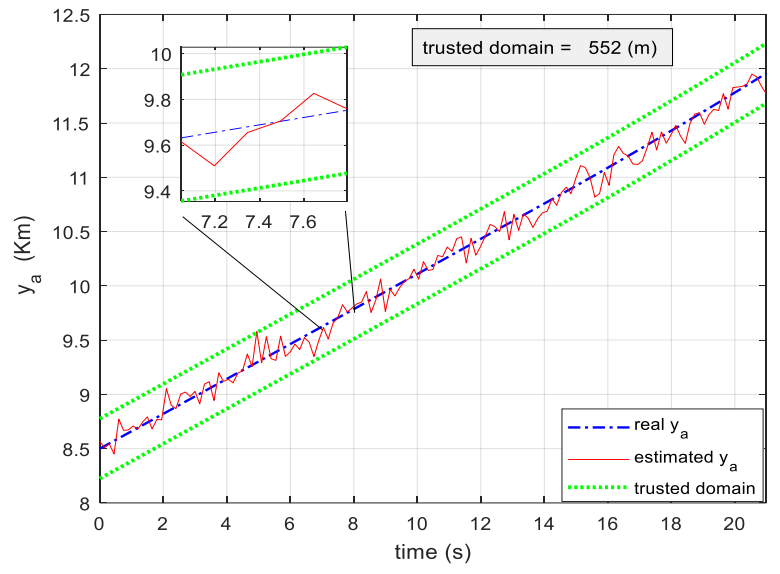

Fig. 9. Real and estimated $\left(y_{a}\right)$ coordinate

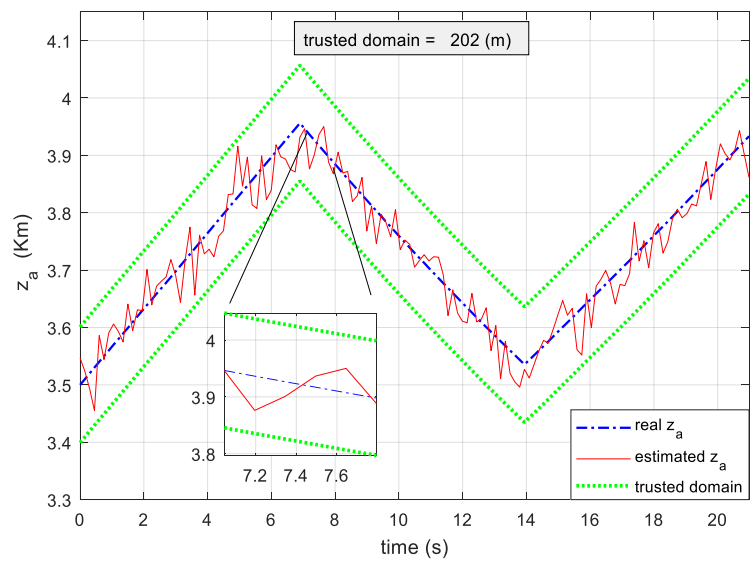

Fig. 10. Real and estimated $\left(z_{a}\right)$ coordinate
In observing the fluctuations in the estimated coordinates, we find that they are caused by the estimations accuracies of the parameters $\left(\theta, \varphi, R_{M}\right.$ and $\left.R C S\right)$, whereas the improvement of the estimation accuracy of each parameter will enhance the estimation accuracy of the target coordinates.

Improving the parameter (SNR) will enhance the simulation results because it affects the estimation of the two arrival angles of the target's echo signal.

By comparing the simulation results with results of other researches [14], [16], we notice Table II, which illustrates the efficiency of the proposed passive radar system in terms of estimation accuracy, system complexity and an appearance of the ghost target phenomenon, with taking into consideration that the system complexity and the mentioned phenomenon are related to the number of the transmitter-receiver pairs.

TABLE II

COMPARISON OF RESULTS

\begin{tabular}{|c|c|c|c|c|}
\hline \multicolumn{5}{|c|}{ SNR domain of target's echo signal is $\left[\begin{array}{ll}\sim 10 & \sim 15\end{array}\right] d B$} \\
\hline References & $\begin{array}{l}\text { Estimation } \\
\text { accuracy of } \\
\quad\left(x_{a}\right) \\
\text { coordinate }\end{array}$ & $\begin{array}{l}\text { Estimation } \\
\text { accuracy of } \\
\quad\left(y_{a}\right) \\
\text { coordinate }\end{array}$ & $\begin{array}{l}\text { Estimation } \\
\text { accuracy of } \\
\quad\left(z_{a}\right) \\
\text { coordinate }\end{array}$ & $\begin{array}{c}\text { Ghost } \\
\text { target } \\
\text { phenomenon }\end{array}$ \\
\hline Results of [14] & \multirow{3}{*}{$\begin{array}{c}\sim\left[\begin{array}{cc}500 & 750\end{array}\right] \\
\quad(m)\end{array}$} & \multirow{3}{*}{$\sim 750(\mathrm{~m})$} & \multirow{3}{*}{$\sim 1000(\mathrm{~m})$} & \multirow{6}{*}{$\begin{array}{l}\text { Existed } \\
\text { (It is } \\
\text { related to a } \\
\text { method of } \\
\text { processing) }\end{array}$} \\
\hline$\left(3 T_{x}, 1 R_{x}\right)$ & & & & \\
\hline $3\left(\mathrm{~T}_{\mathrm{x}}-R_{x}\right)$ pairs & & & & \\
\hline Results of [16] & \multirow{3}{*}{\multicolumn{2}{|c|}{$\begin{array}{l}\text { Hundreds of meters and } \\
\text { decreases to tens of meters }\end{array}$}} & \multirow{3}{*}{$\begin{array}{c}\text { Over } \\
1(\mathrm{~km}) \text { and } \\
\text { decreases } \\
\text { to hundreds } \\
\text { of meters }\end{array}$} & \\
\hline$\left(3 T_{x}, 1 R_{x}\right)$ & & & & \\
\hline $3\left(\mathrm{~T}_{\mathrm{x}}-R_{x}\right)$ pairs & & & & \\
\hline $\begin{array}{l}\text { Results of this } \\
\text { paper }\end{array}$ & \multirow{3}{*}{$\sim 97(m)$} & \multirow{3}{*}{$\sim 92(m)$} & \multirow{3}{*}{$\sim 34(m)$} & \multirow{3}{*}{$\begin{array}{c}\text { Not } \\
\text { existed }\end{array}$} \\
\hline$\left(1 T_{x}, 1 R_{x}\right)$ & & & & \\
\hline $1\left(\mathrm{~T}_{\mathrm{x}}-R_{x}\right)$ pair & & & & \\
\hline
\end{tabular}

Through Table II, we notice that the processing of the proposed passive radar geometry develops applications of passive radars by decreasing the complexity of their system, cancelling the ghost target phenomenon and improving the estimation accuracy of the target coordinates.

\section{CONCLUSION}

In this paper, a new method was proposed to estimate Cartesian coordinates of a target by a passive radar system with a single non-cooperative transmitter and a single receiver. The proposed method depends on analyzing a signal-to-noise ratio and estimating two arrival angles for the target's echo signal. By simulating the proposed passive radar system, we presented the estimating of Cartesian coordinates of the target and the mitigating of disadvantages of using a diversity of receivers or non-cooperative transmitters. We showed the efficiency of the proposed passive radar system by comparing results of this research with results of other researches at convergent simulation conditions. 


\section{REFERENCES}

[1] H. Kuschel, D. Cristallini and K. E. Olsen, "Tutorial: Passive Radar Tutorial," IEEE Aerospace and Electronic Systems Magazine, vol.34, no.2, pp.2-19, 2019, DOI: 10.1109/MAES.2018.160146.

[2] V. Basavarajappa,"Design of a wideband conformal array antenna system with beamforming and null steering, for application in a DVB-T based passive radar," M.S. thesis, Department of Telecommunications, Delft University of Technology, Fraunhofer, 2012.

[3] K. Jeshy, "Tracking of maneuvering targets by passive radar with Gaussian Particle filter," Ph.D. dissertation, National Institute of Telecommunications, Pierre and Marie Curie University , Paris, France, 2012, (In French).

[4] D. W. O'hagan, H. Kuschel, J. Heckenbach, M. Ummenhofer, and J. Schell, "Signal reconstruction as an effective means of detecting targets in a DAB-based PBR," in 11-th International Radar Symposium, IEEE, pp. 1-4, 2010.

[5] M. Conti, C. Moscardini, A. Capria, and R. Soleti, " Estimation of passive bistatic radar detection probability: Experimental results," in 2014 11th European Radar Conference, IEEE, pp. 125-128, 2014, DOI: 10.1109/eurad.2014.6991223.

[6] P. E. Howland, D. Maksimiuk, and G. Reitsma, "FM radio based bistatic radar," IEE Proceedings-Radar, Sonar and Navigation, vol.152, no. 3, pp. 107-115, 2005, DOI: 10.1049/ip-rsn:20045077.

[7] M. Radmard, F. Behnia and M. Bastani, "Cross ambiguity function analysis of the'8k-mode'DVB-T for passive radar application," in 2010 IEEE Radar Conference, IEEE, pp. 242-246, 2010, DOI 10.1109/radar.2010.5494617

[8] J. E. Palmer, H. A. Harms, S. J. Searle, and L. M. Davis, "DVB-T passive radar signal processing," IEEE transactions on Signal Processing, vol.61, no. 8, pp. 2116-2126, April 2013, DOI 10.1109/TSP.2012.2236324.

[9] T. Martelli, F. Colone, E. Tilli, A. Di Lallo, "Multi-Frequency Target Detection Techniques for DVB-T Based Passive Radar Sensors," Sensors, vol.16, no.10, 2016, DOI: 10.3390/s16101594.

[10] H.D. Griffiths, "PASSIVE BISTATIC RADAR AND WAVEFORM DIVERSITY," Defense Academy of the United Kingdom Shrivenham, United Kingdom, 2009.

[11] G. E. Lange, "Performance Prediction and Improvement of a Bistatic Passive Coherent Location Radar," M.S. thesis, Department of Electrical Engineering, University of Cape Town, 2009.

[12] R. Tao, H. Z. Wu, and T. Shan, "Direct-path suppression by spatial filtering in digital television terrestrial broadcasting-based passive radar," IET radar, sonar \& navigation, vol.4, no. 6, pp. 791-805, 2010, DOI: 10.1049/iet-rsn.2009.0138.

[13] M. Malanowski, "Algorithm for target tracking using passive radar." International Journal of Electronics and Telecommunications, vol. 58, no. 4, pp. 345-350, 2012, DOI 10.2478/v10177-012-0047-x.

[14] M. Malanowski, and K. Kulpa. "Two methods for target localization in multistatic passive radar," IEEE transactions on Aerospace and Electronic Systems, vol.48, no. 1, pp. 572-580, 2012, DOI 10.1109/taes.2012.6129656.

[15] M. Wielgo, P. Krysik, K. Klincewicz, L. Maslikowski, S. Rzewuski, and K. Kulpa, "Doppler only localization in GSM-based passive radar." in 2014 International Radar Conference, IEEE, pp. 1-6, 2014, DOI: 10.1109/radar.2014.7060406.

[16] M. Malanowski, K. Kulpa, and R. Suchozebrski. "Two-stage tracking algorithm for passive radar," in 2009 12th International Conference on Information Fusion, IEEE, pp. 1800-1806, 2009.

[17] X. Yin, T. Pedersen, P. Blattnig, A. Jaquier, and B. H. Fleury," A singlestage target tracking algorithm for multistatic DVB-T passive radar systems," in 2009 IEEE 13th Digital Signal Processing Workshop and 5th IEEE Signal Processing Education Workshop, IEEE, pp. 518-523, 2009, DOI:10.1109/dsp.2009.4785978.

[18] W. Jun, Q. Zhaotao, G. Fei, and W. Shaoming, "An Approximate Maximum Likelihood Algorithm for Target Localization in Multistatic Passive Radar," Chinese Journal of Electronics, vol.28, no. 1, pp.195201, 2019, DOI: 10.1049/cje.2018.02.018.

[19] D. E. Hack, L. K. Patton, A. D. Kerrick, and M. A. Saville, "Direct Cartesian detection, localization, and de-ghosting for passive multistatic radar," in 2012 IEEE 7th Sensor Array and Multichannel Signal Processing Workshop (SAM), IEEE, pp. 45-48, 2012.
[20] C. Shi, F. Wang, S. Salous, and J. Zhou, "Performance analysis for joint target parameter estimation in UMTS-based passive multistatic radar with antenna arrays using modified Cramér-Rao lower bounds," Sensors, vol.17, no. 10, 2017, DOI: 10.3390/s17102379.

[21] S. M. Herman, "particle filtering approach to joint passive radar tracking and target classification," Ph.D. dissertation, Graduate College, University of Illinois, Urbana-Champaign, 2002, p: 85.

[22] S. Searle, L. Davis, and J. Palmer, "Signal processing considerations for passive radar with a single receiver," in 2015 IEEE International Conference on Acoustics, Speech and Signal Processing (ICASSP), pp. 5560-5564, April 2015, DOI: 10.1109/icassp.2015.7179035.

[23] O. Mahfoudia, F. Horlin, and X. Neyt, "On the feasibility of DVB-T based passive radar with a single receiver channel," International Conference on Radar Systems, 2017, DOI: 10.1049/cp.2017.0403.

[24] G. Fang, J. Yi, X. Wan, Y. Liu, and H. Ke, "Experimental research of multistatic passive radar with a single antenna for drone detection," IEEE Access, vol.6, pp. 33542-33551, 2018, DOI: 10.1109/access.2018.2844556.

[25] M. Karataş, "A multi foci closed curve: Cassini oval, its properties and applications," Naval Postgraduate School, vol. 14, no. 2, pp. 231-248, 2013.

[26] N. P. Waweru, D. B. O. Konditi, and P. K. Langat, "Performance analysis of MUSIC, root-MUSIC and ESPRIT DOA estimation algorithm," International Journal of Electrical, Computer, Energetic, Electronic and Communication Engineering, vol.8, no. 1, pp. 209-216, 2014.

[27] M. Jalali, M. N. Moghaddasi, and A. Habibzadeh, "Comparing accuracy for ML, MUSIC, ROOT-MUSIC and spatially smoothed algorithms for 2 users," in 2009 Mediterranean Microwave Symposium (MMS), IEEE, pp. 1-5, 2009, DOI: 10.1109/mms.2009.5409832.

[28] W. Nie, K. Xu, D. Feng, C. Q. Wu, A. Hou, and X. Yin, "A fast algorithm for 2D DOA estimation using an omnidirectional sensor array," Sensors, vol.17, no. 3, 2017, DOI: 10.3390/s17030515.

[29] D. L. YANG, W. T. LIU, Q. L. CHENG, Z. X. XIA, and X. F. ZHANG, "2D-DOA Estimation for Coprime L-shaped Arrays with MUSIC Algorithm," DEStech Transactions on Computer Science and Engineering cece, 2017, DOI: 10.12783/dtcse/cece2017/14456.

[30] H. Xu, Y. Zhang, B. Ba, D. Wang and X. Li, "Two-Dimensional Direction-of-Arrival Fast Estimation of Multiple Signals with Matrix Completion Theory in Coprime Planar Array," Sensors, vol. 18, no. 6, pp. 1-14, 2018, DOI: 10.3390/s18061741.

[31] S. Kiani, A. M. Pezeshk, "A Comparative Study of Several Array Geometries for 2D DOA Estimation," Procedia Computer Science, vol. 58, pp. 15-25, 2015, DOI: 10.1016/j.procs.2015.08.004.

[32] M. Meller, "On Bayesian Tracking and Prediction of Radar Cross Section," IEEE Transactions on Aerospace and Electronic Systems, 2018, DOI: 10.1109/TAES.2018.2875572.

[33] J. Torstensson and M. Trieb, "Particle Filtering for Track Before Detect Applications," M. S. thesis, Linkoping University, Sweden, 2005, p. 4150. [Online]. Available: http://www.diva-portal.org/smash/get/diva2:205 09/FULLTEXT01.pdf.

[34] J. W. Crispn and A. L. Maffett, "Radar cross-section estimation for complex shapes," Proceedings of the IEEE, vol. 53, no. 8, pp. 972-982, 1965, DOI: 10.1109/proc.1965.4076.

[35] M. G. Rutten, N. J. Gordon, and S. Maskell, "Recursive track-beforedetect with target amplitude fluctuations," IEE Proceedings-Radar, Sonar and Navigation, vol. 152, no. 5, pp. 345-352, 2005, DOI: 10.1049/ip-rsn:20045041

[36] A. Ziadi, "Deterministic Guassian Particles in Non-Linear Maximum Likelihood: Application of Optimal Filtering for Radar and GPS Signals," Ph.D. dissertation, LAAS Laboratory, France, 2007, (In French).

[37] A. Kazem "Generalized Deterministic Particles in Non-Linear Filtering: Defence Applications and Telecommunications," Ph.D. dissertation, LAAS Laboratory, France, 2008, (In French).

[38] M. Mertense and M. Ulmke, "Ground Target Tracking with RCS Estimation Utilizing Probability Hypothesis Density Filters," in Proceedings of the 16th International Conference on Information Fusion, IEEE, pp. 2145-2152, 2013. 
[39] R. G. White, “A simulated annealing algorithm for radar cross section estimation and segmentation," Applications of Artificial Neural Networks, vol. 2243, pp. 231-241, 1994, DOI: 10.1117/12.169970.

[40] J. Ochodnicky, Z. Matousek, M. Sostronek and A. Hykel, "Radar Cross Section Measurement by Subscale Models," in 2008 International Radar Symposium, IEEE, pp. 1-4, 2008, DOI: 10.1109/irs.2008.4585769.

[41] K. Liao, J. Si, F. Zhu and A. X. He, "Radar HRRP Target Recognition Based on Concatenated Deep Neural Networks," IEEE Access, vol.6, pp. 29211-29218, 2018, DOI: 10.1109/access.2018.2842687.

[42] P. Ptak, J. Hartikka, M. Ritola and T. Kauranne, "Aircraft classification based on radar cross section of long-range trajectories," IEEE Transactions on Aerospace and Electronic Systems, vol. 51, no. 4, pp. 3099-3106, 2015, DOI: 10.1109/taes.2015.150139.

[43] N. J. Willis and H.D. Griffiths, "Air Surveillance" in Advances in Bistatic Radar, SciTech Publishing, Inc., 2007.

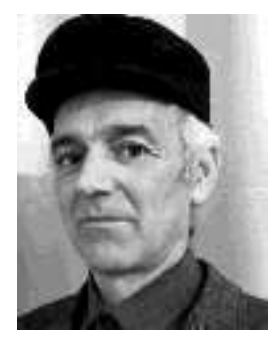

A. Kazem was born in Homs, Syrian Arab Republic in 1970. He received the Engineering and DES degrees in 1994, from the Higher Institute for Applied Sciences and Technology (HIAST), Damascus, Syria. He received his DEA degree in Automatics and Signal Processing in 2003, from the Laboratory for Analysis and Architecture of Systems (LAAS), Toulouse, France. In 2007, he received the Ph.D. degree in Random Signal Processing/Nonlinear Filtering from LAAS-CNRS. He worked as a research engineer with HIAST, Alcatel Alena Space-France, and DSI (Distribution Services Industrials), Toulouse, France. His research interests include statistical signal processing and its applications in radar, sonar, wireless communication systems, and identification systems. Since 2010, he has been a researcher in the Department of Electronic Engineering, HIAST, Damascus-Syria.

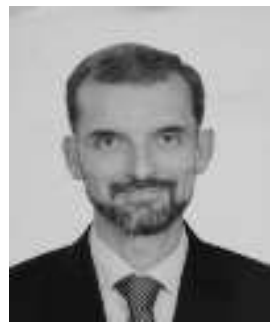

A. Malki was born in Damascus, Syrian Arab Republic in 1956. He received his Electrical Engineering degree (Honor) in 1979, from Damascus University. He received his DEA degree in Electronics in 1982, from the National Higher School of Aeronautics and Space, Toulouse, France. He received his Ph.D. degree in Electronics/ Microwave Circuit Design in 1985 from the National Higher School of Aeronautics and Space, Toulouse, France. During that period he worked with Thomson CSF, Space division at Toulouse, France. His main research interests include: design and development of a wide variety of microwave components and subsystems, such as filters, directional couplers, detectors, LNAs, medium and high power amplifiers, frequency synthesizers, $\mathrm{RF}$ and Microwave front ends. He is a senior professor at the Higher Institute for Applied Sciences and Technology (HIAST), Damascus, Syria.

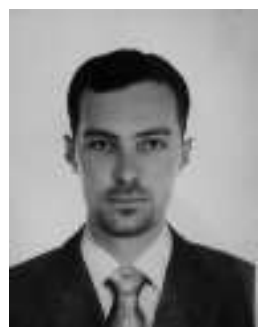

A. M. Almanofi was born in Damascus, Syrian Arab Republic in 1987. Received the Communication and Electronics engineering degree in 2011 from Damascus University. He received his Master degree in Communication from the Higher Institute for Applied Sciences and Technology (HIAST) in 2015. He is currently pursuing the Ph.D. degree in a Passive Radar System at (HIAST). His research interests are in localizing a target in Cartesian coordinates and estimating parameters of a maneuvering target by Particle Filter. 